\title{
ESPÉCIES NOVAS DE LANTHANOMELISSA HOLMBERG E LANTHANELLA MICHENER \& MOURE (HYMENOPTERA, ANTHOPHORIDAE, EXOMALOPSINAE)
}

\author{
Danúncia Urban ${ }^{2}$
}

\begin{abstract}
NEW SPICIES OF LANTHANOMEIISSA HOLMBERG ANI) LANTIIANELLAA

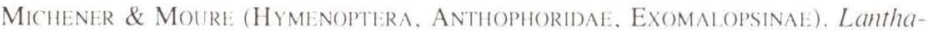
nomelissa pampicola. sp.n.. Lanthanomelissa magaliae. sp.n.. Lanthanomelissa betinae, sp.n., and Lanthanomelissa clementis, sp.n. from southern Brazil. and Lanthanella luciane, sp.n. from Argentina are described.

KEY WORDS. Exomalopsinae. Apoidea, Lanthanomelissa. Lanthanella, taxonomy, Neotropical
\end{abstract}

Tendo recebido para identificação, abelhas coletadas por pesquisadores do convênio entre a Pontifícia Universidade Católica do Rio Grande do Sul (Brasil) e Universidade de Tübingen (Alemanha), foram constatadas quatro espécies novas de Lanthanomelissa Holmberg, 1903 e uma de Lanthanella Michener \& Moure, 1957. O material tipo está depositado no Laboratório de Pesquisas Biológicas da Pontifícia Universidade Católica do Rio Grande do Sul (PUCRS) e na Coleção de Entomologia Pe. J.S. Moure do Departamento de Zoologia da Universidade Federal do Paraná (DZUP).

HOLMBERG (1903) descreveu o gênero e a espécie Lanthanomelissa discrepans baseado em exemplares da Argentina e, na descrição, citou a coloração amarela do escapo, labro e clípeo como também na base ondulada dos tergos; no macho estudado faltava o abdome. MiCHENER \& MOURE (1957), ao caracterizarem o sub-gênero Lanthanomelissa consideraram L. discrepans como sinônimo de Tetrapedia goeldiana Friese, 1899. Pela descrição, Tetrapedia goeldiana difere de Lanthanomelissa. Segundo FrIESE (1899) Tetrapedia goeldiana tem: "segmento anali rotundato, segmentis ventralibus flavis, 3.-5... longe albido-fimbriatis;" "sechstes... kahl", ou seja, o segmento anal arredondado, segmentos ventrais amarelos, terceiro ao quinto com franja longa branca, sexto glabro. Em Lanthanomelissa o segmento distal é alongado e com placa pigidial longa e estreita, esternos acastanhados com áreas amarelas, franjas apicais do segundo ao quinto esterno amarelo-acastanhadas claras e o sexto esterno com tufo distal denso de pêlos curtos. Além destas características, Lanthanomelissa tem duas células sub-marginais nas asas anteriores e esterno basal com pilosidade muito curta, densa e decumbente

1) Contribuição número 893 do Departamento de Zoologia. Universidade Federal do Paraná.

2) Departamento de Zoologia. Universidade Federal do Paraná. Caixa Postal 19020. 81531-990) Curitiba, Paraná, Brasil. 
até a margem. Na fêmea os basitarsos anteriores são achatados e largos no lado ventral, aí um pouco côncavos ao longo do comprimento, quase glabros, margeados largamente no bordo anterior por cerdas grossas curtas arqueadas.

\section{Lanthanomelissa betinae, sp.n.}

Fig. 1

Lanthanomelissa sp.: Oliveira, 1966, Studia Ent. 9: 429-440).

Lanthanomelissa goeldiana: Sakagami \& Laroca, 1988. J. Kansas Ent. Soc. 6 (3): 347-349.

Oliveira (1966) descrevendo larvas de Lanthanomelissa coletadas por Sebastião Laroca em Castro (Paraná), em ninhos agregados, não obteve a identificação da espécie. SAKAGAMI \& LAROCA (1988) publicaram suas observações sobre os ninhos encontrados em Castro, tendo Pe.J.S. Moure interpretado a espécie como Lanthanomelissa goeldiana. Esse material, duas fêmeas, foi examinado na elaboração deste trabalho e consta na listagem dos parátipos de L. betinae, sp.n.

Diagnose. Escapo preto; macho com a franja do quinto esterno emarginada medianamente, os pêlos afastados do bordo no meio e mais curtos deixando ver o tegumento; fêmures posteriores com pilosidade alongada na face posterior, pêlos mais longos que o diâmetro do flagelo misturados com pêlos curtos; fêmea com labro, clípeo e flagelômeros basais enegrecidos; sexto esterno sem áreas glabras subapicais, tufo normal.

Holótipo macho. Tegumento preto na cabeça e mesosoma com as seguintes áreas claras: amarelo na base das mandíbulas e parte do labro; quase todo o clípeo amarelo, preto somente nos cantos; flagelômeros amarelo-acastanhados ventralmente. Pernas amarelas do ápice do fêmur ao tarso, com o lado ventral das tíbias anteriores castanho e manchas desta côr também no lado interno das demais tíbias. Tergos pretos com nódoas laterais arredondadas amarelas nos três basais, pequenas no primeiro; dois tergos basais com larga faixa marginal translúcida castanha nos flancos, terceiro com área preta disco-basal e para o ápice castanho escuro; quarto ao sexto tergo com faixa basal amarela larga e margem também larga, acastanhada no quarto tergo, mais clara nos seguintes; esternos enegrecidos passando a castanho-amarelados, com esbranquiçado no ápice.

Pilosidade da cabeça castanho-clara; castanha no mesoscuto, escutelo e nos tergos, amarela levemente acastanhada nas pernas; castanho-clara nas franjas esternais, porção mediana do segundo ao quarto esterno com franja densa, os pêlos voltados para o meio e os laterais mais longos que o medianos; no quinto com profunda emarginação mediana acompanhando a emarginação do esterno, mais curta em pequena área mediana, deixando ver o tegumento, e com os pêlos laterais longos convergentes para o meio; sexto com pilosidade fina no disco.

Comprimento aproximado $6,17 \mathrm{~mm}$; largura da cabeça $2,32 \mathrm{~mm}$; comprimento do olho $1,34 \mathrm{~mm}$.

Variações. Mandíbulas e labro inteiramente pretos, mandíbulas com nódoa castanha basal em vez de amarela e labro quase todo amarelo; além de nódoa amarela na base das tégulas, nódoas amarelas nos lobos pronotais, na face dorsal do pronoto e metanoto. Pilosidade do mesoscuto esbranquiçada até castanha. 

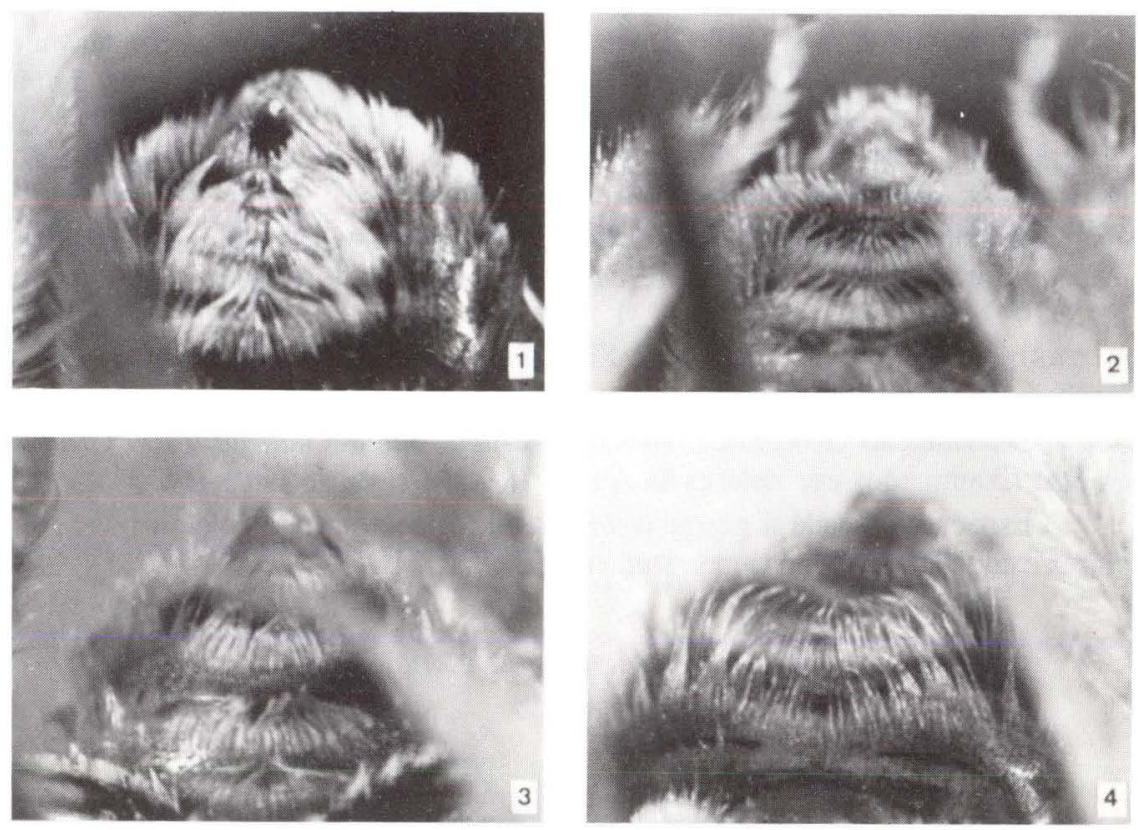

Figs 1-4. Esternos dos machos de Lanthanomelissa. (1) L. betinae; (2) L. magaliae; (3) L. pampicola; (4) L. discrepans.

Alótipo fêmea. Cabeça e mesosoma pretos; flagelômeros com a face ventral amarelo-acastanhada a partir do segundo até o distal. Pernas mais escuras do que no macho, pretas quase até o ápice dos fêmures, tíbias anteriores só com o lado dorsal amarelo, demais tíbias com o castanho predominando; basitarsos anteriores amarelo-acastanhados na face ventral, os restantes castanhos. Tergos e esternos como no macho.

Pilosidade branca a levemente acastanhada; amarelo-acastanhada nas pernas; franjas bissinuosas do segundo ao quarto esterno com pêlos lisos castanhoclaros no meio; sexto esterno sem áreas glabras subapicais no tufo distal.

Comprimento aproximado $6,33 \mathrm{~mm}$; largura da cabeça $2,28 \mathrm{~mm}$; comprimento do olho $1,36 \mathrm{~mm}$.

Variações. Entre as fêmeas coletadas em Seara, uma com o clípeo preto, uma com o disco do clípeo amarelo como no macho descrito, com os cantos do clípeo pretos e o labro enegrecido, uma com o clípeo quase todo amarelo e pequena área supraclipeal amarela, e uma com estrias pretas sobre o amarelo; nas duas fêmeas coletadas em Castro, o clípeo como no macho descrito e o labro enegrecido. No tegumento das pernas, foi observado o aumento da área escura, reduzindo a área amarela das tíbias medianas e as posteriores passando a castanho-enegrecidas, basitarsos medianos e posteriores castanhos e demais tarsômeros também desta cor. 
Holótipo macho, alótipo fêmea e um parátipo macho. BRASIL, Rio Grande do Sul: Gramado, 17-XI-1990, B. Blochtein leg. (DzuP). Parátipos de Santa Catarina: Seara (Nova Teutônia), três machos e três fêmeas, XI-1951, F. Plaumann leg. (DZUP); uma fêmea, X-1948 (DZUP); Paraná: Castro, duas fêmeas, IX-1961 e X-1961, Sakagami \& Laroca leg. (DZUP). Parátipos do Rio Grande do Sul: Gramado, três machos, 16-XI-1992, B. Blochtein leg. (PUCRS); Osório, dois machos e uma fêmea, 12-X-1991, I.A. dos Santos leg. (PUCRS); duas fềmeas, 23-X-1992 (PUCRS); uma fêmea, 24-X-1992 (PUCRS); uma fêmea, 16-XI-1992 (PUCRS); Cruz Alta, um macho, 2-XI-1990, B. Blochtein leg. (PUCRS); cinco machos, 3-XI-1990 (PUCRS).

Distribuição Geográfica. Brasil: Paraná, Santa Catarina e Rio Grande do Sul. Examinados exemplares da Argentina: Misiones e Entre Rios.

Espécie dedicada à pesquisadora Betina Blochtein que coletou os exemplares estudados e se dedica ao estudo das abelhas.

\section{Lanthanomelissa clementis, sp.n.}

Figs 5-7

Diagnose. Macho com o escapo inteiramente preto ou com nódoas amarelas, clípeo amarelo, franja do quinto esterno semelhante à dos esternos anteriores na forma, porém com pêlos de tamanho uniforme; fêmures posteriores com pêlos curtos de tamanho uniforme na face posterior, menores que o diâmetro do flagelo; fêmea com escapo preto, labro e clípeo pretos com áreas amarelas variáveis. flagelômeros basais amarelo-acastanhados ventralmente, sexto esterno com duas áreas subapicais glabras no tufo distal.

Holótipo macho. Tegumento preto na cabeça e mesosoma, com as seguintes áreas claras: amarelo no labro, clípeo, metade basal das mandíbulas e nódoa na área supraclipeal; lado ventral do flagelo amarelo-acastanhado. Tégulas castanhoenegrecidas com nódoa basal amarela; pernas anteriores e medianas amarelas a partir do ápice do fêmures até os tarsos, nas posteriores o amarelo ocupando o terço apical dos fêmures até os tarsos. Tergo basal preto com duas nódoas amarelas laterais pequenas; do segundo ao quarto tergo largamente pretos na parte mediana até a margem, com grandes nódoas amarelas arredondadas laterais deixando margem translúcida amarelo-acastanhada nos flancos, maiores no quarto; quinto tergo com as nódoas amarelas quase fundidas no meio, com pequena área discal preta e margem amarelada translúcida; sexto amarelo na base e com margem translúcida amarelo-acastanhada, desta côr também o sétimo; esternos castanhos, o apical com área distal amarelo-acastanhada.

Pilosidade branca na cabeça, mesosoma, parte das pernas e nos tergos; amarelo-acastanhada nas tíbias e basitarsos posteriores e nas franjas dos esternos. Franja densa do segundo ao quarto esterno com pélos mais longos laterais voltados para o meio, no segundo os pêlos esparsos no meio, quinto com franja densa alongada ocupando quase todo o bordo, sem pêlos mais curtos no meio e em arco rebaixado; sexto com pilosidade fina no disco. 

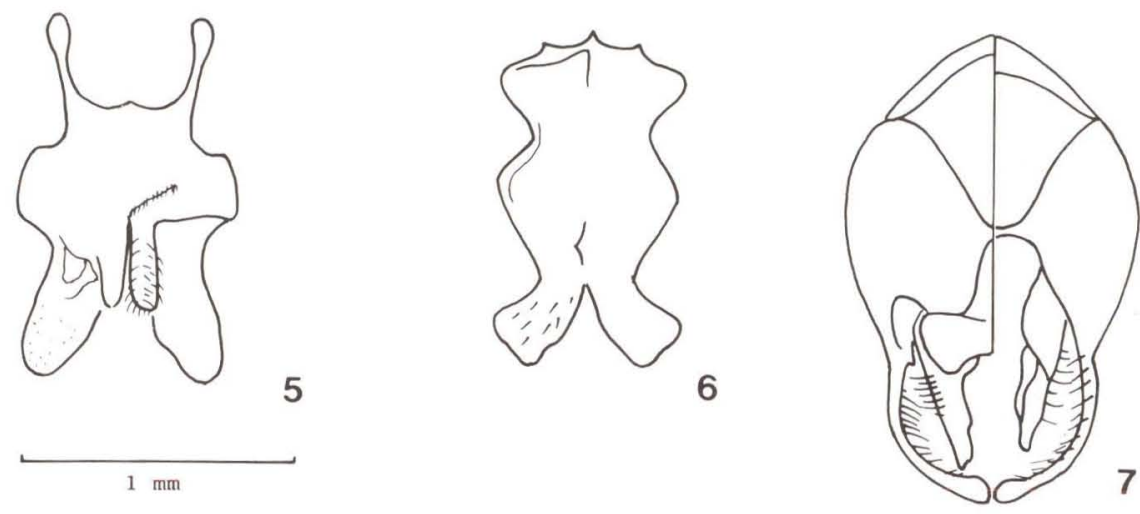

Figs 5-7. Macho de Lanthanomelissa clementis. (5) sétimo esterno; (6) oitavo esterno; (7) genitália com a metade ventral no lado direito.

Comprimento aproximado $6,58 \mathrm{~mm}$; largura da cabeça $2,12 \mathrm{~mm}$; comprimento do olho $1,32 \mathrm{~mm}$.

Variações. Principalmente no colorido do escapo, que pode ser inteiramente preto, com pequena nódoa amarela na face anterior, ou com toda a face anterior amarela, com duas nódoas irregulares em cada escapo ou com uma nódoa amarela pequena no escapo esquerdo e a nódoa grande no outro escapo do mesmo exemplar; paroculares inferiores de alguns exemplares com nódoa arredondada, nódoa só em uma das paroculares inferiores, manchas amarelas acastanhadas ou ainda nódoas grandes ocupando toda a área junto ao clípeo. Um parátipo, macho, coletado juntamente com o holótipo, com duas áreas negras alongadas no clípeo, porém assimétricas e no mesmo exemplar com redução do amarelo nos tergos. Constatadas também pequenas áreas amarelas nos flancos do metanoto, áreas amarelas acastanhadas nas tíbias e basitarsos posteriores e o sexto esterno com grande nódoa amarela basal.

Alótipo fêmea. Cabeça preta, labro e metade apical do clípeo castanhoescuros; lado ventral dos flagelômeros amarelo-acastanhado. Mesosoma preto; pernas amarelo-acastanhadas com áreas castanhas do ápice do fêmur aos tarsos, castanhas na face posterior de todas as tíbias e dos basitarsos posteriores. Tergos castanhos escuros; quatro tergos basais com nódoas laterais amarelas, pequenas no primeiro, grandes no segundo e terceiro, e avançando para o meio no quarto; grandes nódoas amarelas laterais no quinto tergo quase fundidas no meio; esternos pretos.

Pilosidade branca; nas tíbias e basitarsos posteriores amarelo-acastanhada; franja bissinuosa do segundo ao quarto esterno, os pêlos lisos castanho-claros no meio do segundo e do terceiro; sexto esterno com pêlos discais convergentes para o meio e os do tufo apical curtos eretos e lateralmente separados pelas duas áreas glabras subapicais. 
Comprimento aproximado $5,83 \mathrm{~mm}$; largura da cabeça $2,28 \mathrm{~mm}$; comprimento do olho $1,36 \mathrm{~mm}$.

Variações do tegumento. Mais notáveis no colorido do labro e do clípeo. O labro mais castanho até amarelo levemente acastanhado e o clípeo com larga margem acastanhada ou amarela, prolongada estreitamente até a base no meio, em exemplares coletados juntamente com o alótipo. Parátipos de Caçapava do Sul com pequena nódoa amarela na base do clípeo e o restante amarelo-acastanhado, clípeo amarelo com duas nódoas látero-basais pretas, e nódoas amarelas ou amareloacastanhadas nas mandíbulas. Também observada a ocorrência de faixa amarela completa no quinto tergo.

Holótipo macho. Brasil, Rio Grande do Sul: Guaíba, 13-X-1990, C. Schlindwein leg. (DZUP). Alótipo fêmea e dois parátipos fêmeas da mesma localidade e mesmo coletor, 3-XI-1990 (DZUP); dois parátipos machos com os mesmos dados do holótipo (DZuP); Santa Catarina: Seara (Nova Teutônia), F. Plaumann leg., dois machos, X-1951 e XI-1951 (DZUP). Parátipos do Rio Grande do Sul: 12 machos com os mesmos dados do holótipo (PUCRS); Guaíba, duas fêmeas, 2-XI-1990, C. Shlindwein leg. (PUCRS); sete fềmeas, 13-XI-1990 (PUCRS); Guaíba, uma fêmea, 23-XI-1990, B. Blochtein leg. (PUCRS); Canguçu, Morro Redondo, 10 machos, 16-XI-1990, C. Schlindwein leg. (PUCRS); Canguçu, Posto Branco, duas fêmeas, 17-XI-1990, C. Schlindwein leg. (PUCRS); Caçapava do Sul (Guaritas), um macho, 08-X-1991, C. Schlindwein leg. (PUCRS); duas fêmeas, 10-X-1991 (PUCRS); seis fêmeas, 11-X-1991 (PUCRS); um macho, 26-X-1991 (PUCRS); cinco fêmeas, 14-X-1992 (PUCRS); Porto Alegre (Viveiro Municipal), uma fêmea, 10-XI-1989 C. Schlindwein leg. (PUCRS).

Distribuição Geográfica. Brasil: Samta Catarina e Rio Grande do Sul. Examinados também exemplares da Argentina: Misiones.

Espécie dedicada ao pesquisador Clemens Schlindwein que coletou o material estudado.

\section{Lanthanomelissa magaliae, sp.n.}

Fig. 2

Diagnose. Escapo amarelo ornado com estria lateral externa preta; macho com flagelômeros crenulados na face lateral externa; franja densa do segundo esterno sem pêlos muito longos encurvados para o meio, quinto esterno com pêlos mais curtos no meio e ladeados por pêlos mais longos voltados para os flancos; sexto com tufo piloso discal.

Holótipo macho. Tegumento preto com as seguintes áreas claras: amarelo na metade basal das mandíbulas, labro, clípeo, grande nódoa arredondada na área supraclipeal, nódoa nas paroculares inferiores junto ao clípeo; escapo amarelo com estria preta lateral externa; face dorsal do flagelo castanho-enegrecida e a ventral amarelo-acastanhada. Pronoto com nódoa amarela nos lobos e faixas amarelas látero-dorsais; tégulas amarelo-acastanhadas com nódoa basal amarela; axilas com nódoa amarela; metanoto com faixa discal amarela; pernas anteriores e medianas 
amarelas a partir do terço apical dos fêmures, nas posteriores a partir da metade apical dos fêmures; com áreas acastanhadas nas tíbias medianas e posteriores e nos basitarsos posteriores. Tergo basal preto com grandes nódoas laterais amarelas, no segundo nódoas amarelas ocupando mais de um terço da largura do tergo e arredondadas, entre as nódoas o tegumento preto acompanhando o bordo das mesmas quase até a margem, nos flancos larga margem amarelo-acastanhada; terceiro e quarto tergos com as nódoas amarelas fundidas estreitamente no meio, castanho-escuros no disco e ápice, com larga margem amarelo-acastanhada nos lados; quinto e sexto amarelo-acastanhados com pouco amarelo na base; sétimo amarelo levemente acastanhado; esternos com áreas castanhas e fracamente amareladas, o distal com nódoa basal amarelada.

Pilosidade branca a levemente amarelo-acastanhada, desta côr nas franjas apicais da porção mediana do segundo ao quinto esterno, as franjas densas com pêlos voltados para o meio, do segundo ao quarto esterno, no quinto mais curta no meio e com os pêlos laterais voltados para os flancos, um pouco mais emarginada que as anteriores; sexto com tufo piloso discal, os pêlos semi-eretos curtos e tufo apical de pêlos curtos eretos.

Comprimento aproximado 5,92 $\mathrm{mm}$; largura da cabeça $2,12 \mathrm{~mm}$; comprimento do olho $1,33 \mathrm{~mm}$.

Variações foram constatadas no tamanho da nódoa amarela supraclipeal e na do sexto esterno. Um macho de Viamão com os tergos mais claros na área marginal; outro macho, de Esteio, com três células sub-marginais na asa direita e duas na asa esquerda onde pode ser visto um vestígio da primeira $\mathrm{r}-\mathrm{m}$.

Holótipo macho. Brasil, Rio Grande do Sul: Viamão, 5-XI-1985, M. Hoffmann leg. (DZUP); um parátipo macho de Esteio, XI-1942, sem indicação de coletor (DZUP); demais parátipos: Viamão, Morro do Coco, um macho, 3-XII1991, C. Schlindwein leg. (PUCRS); Bagé (Casa do Pedro), um macho, 01-XI1992, C. Schlindwein leg. (PUCRS).

Distribuição geográfica. BRASIL: Rio Grande do Sul.

Espécie dedicada à pesquisadora Magali Hoffmann que coletou parte do material e se dedica ao estudo dos Apoidea.

\section{Lanthanomelissa pampicola, sp.n.}

Fig. 3

Diagnose. Escapo amarelo ornado lateralmente com estria preta; macho com flagelômeros lisos, quinto esterno com franja quase reta, sexto esterno quase glabro no disco; fêmea com o clípeo amarelo na margem e preto junto à sutura epistomal, o amarelo prolongado até a sutura no meio, sexto esterno com duas áreas arredondadas subapicais glabras no tufo piloso.

Holótipo macho. Tegumento preto na cabeça e mesosoma, com as seguintes áreas claras: amarelo na metade basal das mandíbulas, labro, clípeo, nódoa de contorno arredondado nas paroculares inferiores junto ao clípeo e pequena mancha na área supraclipeal; escapo amarelo, excetuando pequena área preta no lado 
externo; lado ventral dos flagelômeros amarelo somente nos basais, amareloacastanhado nos restantes, castanho no lado dorsal, orla amarela no pedicelo. Nódoa amarela nos lobos pronotais e faixas látero-apicais na parte dorsal do pronoto; tégulas castanhas com nódoa basal amarela; axilas com faixa amarela estreita e metanoto com área discal amarela levemente acastanhada; pernas anteriores amarelas a partir do ápice do fêmur, e as demais amarelas da metade do fêmur até os tarsômeros distais. Primeiro e segundo tergos pretos, o primeiro com duas grandes nódoas laterais amarelas, e o segundo com duas grandes áreas laterais amarelas de contorno arredondado para o meio; terceiro com nódoas amarelas látero-discais, estreitadas para o meio e um pouco separadas uma da outra na linha mediana; do quarto ao sexto tergo com faixa amarela, mais estreita e basal no meio; quatro tergos basais com borda translúcida amarelo-acastanhada nos lados, mais larga para o meio no terceiro e quarto tergos, parte mediana destes tergos castanha escura; quinto e sexto com faixa marginal translúcida amareloacastanhada completa e faixa discal castanho-escura, mais larga no meio porém não chegando aos lados; esternos castanho-amarelados, o distal amarelo levemente ocráceo com castanho nos flancos.

Pilosidade branca, levemente amarelada nas pernas, do segundo ao quinto esterno com franja castanha clara densa e levemente emarginada na porção mediana, com os pêlos laterais convergindo para o meio, a franja quase reta no quinto; sexto esterno quase glabro no disco e na base, com tufo apical piloso.

Comprimento aproximado $5,0 \mathrm{~mm}$; largura da cabeça $2,0 \mathrm{~mm}$; comprimento do olho $1,20 \mathrm{~mm}$.

Variações principalmente nas nódoas amarelas do terceiro e quarto tergos, em forma de grandes nódoas látero-discais bem afastadas uma da outra, ou quase unidas no meio por estreita área basal; também na ausência de faixa estreita amarela nas axilas e no metanoto, e de nódoa amarela na área supraclipeal.

Alotipo fêmea. Semelhante ao macho porém com o tegumento mais escuro. Escapo amarelo com estria preta lateral externa. O clípeo difere pela redução da área clara, o amarelo somente na metade apical e prolongado até a base em faixa estreita, com grandes nódoas látero-basais pretas.

Pilosidade dos esternos formando franja bissinuosa, os pêlos plumosos longos brancos; do segundo ao quarto esterno, no meio da franja, os pêlos castanhos e lisos.

Comprimento aproximado $5,33 \mathrm{~mm}$; largura da cabeça $2,10 \mathrm{~mm}$; comprimento do olho $1,26 \mathrm{~mm}$.

Holótipo macho. Brasil, Rio Grande do Sul: Caçapava do Sul (Guaritas), 9-XI-1991, C. Schlindwein leg. (DZuP). Alótipo fêmea da mesma localidade e mesmo coletor, 26-X-1991 (DZUP); um parátipo macho de Caçapava do Sul (Minas de Camaquã), 27-X-90, S.W. Freitas leg. (DZuP). Parátipos de Caçapava do Sul (Minas de Camaquã), uma fêmea, 25-X-1990, B. Hille leg., (PUCRS); mesma localidade, um macho, 27-X-1990, B. Hille leg., (Pucrs); Caçapava do Sul, Guaritas, uma fêmea, 17.X.92, C. Schlindwein leg. (PUCRS).

Distribuição geográfica. BRASIL: Rio Grande do Sul.

Etimologia. Refere-se à região dos pampas. 


\section{Chave para as espécies de Lanthanomelissa}

1. Machos . . . . . . . . . . . . . . . . . . . . . . . 2

- Fêmeas . . . . . . . . . . . . . . . . . . . . . . . .6.6

2. Escapo inteiramente preto, com nódoas amarelas ou somente com a face anterior amarela. Flagelômeros lisos . . . . . . . . . . . . . . . . . 3

- Escapo inteiramente amarelo ou somente com estria preta na face láteral externa. Flagelômeros lisos ou crenulados . . . . . . . . . . . . . . . 4

3. Fêmures posteriores com pilosidade irregular na face posterior, pêlos mais longos que o diâmetro do flagelo mesclados com pêlos curtos. Segundo ao quarto esterno com pêlos laterais mais longos arqueados para o meio. Quinto esterno com franja profundamente emarginada, deixando ver o tegumento no meio, os pêlos mais curtos e afastados do bordo nesta área . betinae

- Fêmures posteriores com pilosidade curta, ereta e fina, de tamanho uniforme na face posterior, os pêlos mais curtos que o diâmetro do flagelo. Só o segundo esterno com pêlos longos encurvados para o meio; terceiro e quar to esternos com franja apical de tamanho quase uniforme; quinto esterno com franja fracamente sinuada, quase reta, os pêlos encobrindo o tegumento . . . . . .

clementis

4. Escapo amarelo. Segundo esterno com pêlos laterais muito longos nos cantos da franja apical, encurvados para o meio e, na área mediana quase sem pêlos ou glabro (Fig.4); quinto esterno com franja emarginada, nos lados da franja os pêlos voltados para trás. . . . . . . . . . . discrepans

- Escapo amarelo porém com estria preta lateral externa. Segundo esterno com franja densa, sem área quase glabra mediana e sem pêlos laterais muito longos; quinto esterno com franja reta ou em arco rebaixado, os pêlos laterais da franja dirigidos para trás ou voltados para fora . . . . . . . 5

5. Flagelomeros crenulados na face lateral externa. Sexto esterno com tufo piloso no disco. Franja do quinto esterno com os pêlos mais curtos no meio e os laterais dirigidos para os flancos. . . . . . . . . . . magaliae

- Flagelômeros lisos, sem crenulações. Sexto esterno quase glabro no disco e na base. Franja do quinto esterno com pêlos de tamanho uniforme, nos lados da franja os pêlos voltados para trás. . . . . . . . . . pampicola

6. Escapo preto, ou com amarelo somente na face anterior . . . . . . . . . 7

- Escapo amarelo ou com estria preta na face lateral exterior . . . . . . . . 8

7. Sexto esterno com tufo piloso apical normal, desprovido de áreas glabras

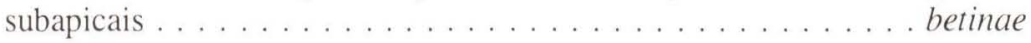

- Sexto esterno com duas áreas glabras subapicais arredondadas denso-pontuadas nos lados do tufo apical . . . . . . . . . . . . . clementis

8. Clípeo amarelo; quando com áreas basais pretas estas muito pequenas. Sexto 
esterno com tufo piloso apical normal, desprovido de áreas glabras sub-

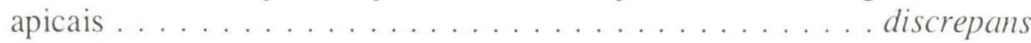

- Clípeo amarelo com áreas látero-basais pretas. Sexto esterno com duas áreas glabras subapicais arredondadas no tufo piloso distal. . . . . . pampicola

Lanthanella tem três células sub-marginais nas asas anteriores. Basitarsos anteriores da fêmea com pente de cerdas curtas no lado externo, e cerdas curtas eretas no lado ventral; mediotarsos anteriores com grande área discal glabra, arredondada no bordo apical e orlada com cerdas encurvadas largas, achatadas e curtas; mesoscuto e escutelo com pêlos curtíssimos mesclados com pêlos longos esparsos. Macho sem placa pigidial distinta; segundo ao quinto esterno com franja apical, menos densa na porção mediana, longa e voltada para o meio lateralmente; mesoscuto com pilosidade longa e densa, com pêlos curtos de permeio no disco, posteriormente.

\section{Lanthanella luciane, sp.n.}

Diagnose. Macho com escapo amarelo e nódoas desta cor no pronoto e no metanoto; pontuação do mesoscuto e escutelo esparsa, os intervalos entre os pontos de dois a quatro diâmetros de ponto.

Holótipo macho. Cabeça e mesosoma pretos com as seguintes áreas claras: amarelo na metade basal das mandíbulas, todo o labro, clípeo, grande parte da área supraclipeal, nódoa nas paroculares inferiores junto ao clípeo, escapo, área discal do pedicelo e parte lateral do primeiro flagelômero; demais flagelômeros amarelo-acastanhados ventralmente e castanhos no lado dorsal. Amarelo nos lobos pronotais, metade apical da face dorsal do pronoto e nódoa no terço basal das tégulas, no restante das tégulas amarelo-acastanhado; metanoto com duas nódoas látero-discais amarelas; axilas e áreas dôrso-laterais do metanoto amarelas, pernas desta cor a partir da metade dos fêmures até os tarsos. Tergos e esternos amarelo-ocráceos pálidos com grandes áreas enegrecidas irregulares no segundo e terceiro tergos.

Pilosidade branca e alongada na cabeça, mais longa no mesosoma, levemente acastanhada no mesoscuto e escutelo; grande parte das pernas anteriores com pêlos brancos, como também nos artículos basais das medianas e posteriores, tíbias e basitarsos amarelados; branca nos tergos. Segundo ao quinto esterno com franja ocrácea pálida.

Comprimento aproximado $6,67 \mathrm{~mm}$; largura da cabeça $2,46 \mathrm{~mm}$; comprimento do olho $1,48 \mathrm{~mm}$.

Variação. Um macho com os tergos de um castanho levemente avermelhado, os dois basais largamente avermelhados nos cantos e com larga margem amarela clara.

Holótipo macho. Argentina, La Pampa: Las Adelas, 26-XI-1973, J.L. Neff leg. (DZUP). Dois parátipos com a mesma procedência e coletor (DZUP).

Distribuição Geográfica. Argentina: La Pampa. 
A espécie é uma homenagem à Profa. Luciane Marinoni pela sua dedicação ao estudo dos insetos.

Comentário. Na única espécie anteriormente conhecida, Lanthanella completa (Michener \& Moure, 1957) o macho tem escapo preto, mesosoma preto sem nódoas amarelas, pontuação do mesoscuto densa, os intervalos igualando o diâmetro dos pontos.

AGRADECIMENTOS. A autora agradece ao Prof. Albino M. Sakakibara pelas fotos e ao Pe. Jesus $S$. Moure pelo acesso à bibliografia.

\section{REFERÊNCIAS BIBLIOGRÁFICAS}

FrIESE, H. 1899. Monographie der Bienengattungen Exomalopsis, Ptilothrix, Melitoma und Tetrapedia. Ann. k.k. nat. Hofmus., Wien, 14 (3): 247-304. HolmberG, E.L. 1903 Delectus Hymenopterologicus Argentinus. An. Mus. Nac., Buenos Aires, 9: 377-468.

OlviveirA, B.L. DE. 1966. Descrição de estádios imaturos de Lanthanomelissa sp. com inferência sôbre a posição filogenética dêste gênero entre os Exomalopsinae (Hym., Apoidea). Studia Ent. 9 (1-4): 429-440.

Michener, C.D. \& J.S. Moure. 1957. A study of the classification of the more primitive non-parasitic Anthophorine bees (Hymenoptera, Apoidea). Bull. Amer. Mus. Nat. Hist. 112 (5): 395-452.

SAKAGAMI, S.F. \& S. LAROCA. 1988. Nests of an Exomalopsine bee Lanthanomelissa goeldiana (Hymenoptera: Anthophoridae). Jour. Kansas Ent. Soc. 61 (3): $347-349$. 